\title{
A mão afro-brasileira. Significado da contribuição artística e histórica ${ }^{1}$
}

\author{
Antonio Dimas \\ Universidade de São Paulo (São Paulo, Brasil)
}

m 2010 saiu, em segunda edição revista e ampliada, A mão afro-brasileira. Significado da contribuição artística e histórica, organizada por Emanoel Araújo. São dois robustos e vistosos volumes, publicados pela Imprensa Oficial do Estado de São Paulo e pelo Museu Afro Brasil, com o patrocínio da EDP e o incentivo do Ministério da Cultura.

A primeira edição é de 1988, em um volume apenas. Entre as duas edições há diferenças substanciais.

Para esta edição de 2010, o organizador preferiu uma divisão em cinco partes, que vêm depois de palavras protocolares de figuras da política e do mundo empresarial, nenhuma delas de maior relevância diante do porte deste empreendimento intelectual e editorial.

Além dessa preferência, o organizador mostrou-se também mais prudente quando, ao reescrever nova apresentação para esta $2^{a}$ edição, alterou de modo nítido a "Introdução e Proposição" da 1 a edição, eliminando o que se lê a seguir: Não é preciso recorrer a pesquisas científicas, ordenadas por conceitos antropológicos acadêmicos para constatar os nossos vínculos com a África (1988, p. 16). De fato, dada a evidência empírica e existencial desses vínculos, a pesquisa científica vem depois, confirmando-os, através de métodos próprios, nem sempre reveladores e cheios de novidade. Hoje em dia, as pesquisas genéticas de ponta, em desenvolvimento no país, continuam corroborando aquilo que a perspicácia pioneira e a sensibilidade social de intelectuais como Sílvio Romero, Manuel Querino, Nina Rodrigues, Gilberto Freyre e Artur Ramos - para ficarmos

1. Org. por Emanoel Araújo. Trad. de Graham Howells. $2^{a}$ ed. rev. e ampl. São Paulo: Imprensa Oficial do Estado de São Paulo-Museu Afro Brasil, 2010. 2 vols. 443 p. + 415 p. ISBN: 978-85-7060-934-2 
com os mais óbvios apenas - vêm afirmando desde a segunda metade do século 19, mesmo que suas afirmações viessem desprotegidas de instrumentos de precisão eletrônica. Não obstante esse descompasso temporal, a pesquisa científica e acadêmica ainda são indispensáveis quando se pretende consolidar aquilo que a percepção fina observa ao vivo e converte em palavras.

O tom de abertura das duas edições é diferente.

Ao registrar seus propósitos em 1988, Emanoel Araújo mostra-se mais combativo. Anos depois, a edição de 2010 atenua seu tom polêmico e comemora: É uma grande celebração ao legado de tantos e tantos artistas, anônimos ou não, que construiram a nossa identidade, que buscaram dentro de seu ser magoado a superação de tão terrivel herança (2010, p. 1-18).

Seguro de que não é mais necessário reivindicar a indiscutível contribuição negra para a arte brasileira e nem exaltar sua presença, Emanoel Araújo dispensa, nesta $2^{a}$ edição, alguns artigos, cuja incisão crítica se impusera de modo mais cortante na edição de 1988.

Por causa dessa escolha editorial, perdeu-se, por exemplo, a perspectiva pioneira de um artigo como o de Nina Rodrigues ("As Belas Artes nos colonos pretos do Brasil”"), cujas limitações metodológicas intrínsecas eram largamente compensadas pelo fato de ter sido artigo publicado em 1904 na revista Kosmos. Em periódico luxuoso, criado para festejar as glórias do afrancesamento carioca fin de siècle, causava espécie a valorização de um veio negro e fundacional da sociedade brasileira. É contradição como essa que explica a autocensura de Nina Rodrigues quando lamentava o sequestro de algumas imagens "desaconselháveis", mas ilustrativas de sua exposição em revista destinada ao público branco: Os atributos fálicos do orichá Eshu [sic] não permitem darmos aqui a fotografia de duas peças de bronze que se acham em meu poder e pertenceram ao bastão ou cetro de um régulo ou potentado africano (1988, p. 179).

Perderam-se, igualmente, as sugestões de classificação estética propostas por Mário Barata (“A escultura de origem negra no Brasil”) ou a ideia de se levantar um corpus sculptorum (1988, p. 185) que desse sustentação às pesquisas relativas ao anel criativo que o crítico sinalizou para o Atlântico Central e no qual se incluem Caribe, Américas e África. Perderam-se ainda os depoimentos fortemente vivenciais de José Cláudio ("Redação sobre a minha cor") ou de Rubem Valentim ("Manifesto ainda que tardio"). O primeiro confessava que, imerso em sua experiência negra e na convivência com sararás de beiços 
estourados, associavava brancura à doença, à anemia, à morte, à branquidez dos cadáveres (1988, p. 292). Rubem Valentim, por sua vez, interrompia a linguagem concretista do seu momento, que é o de 1976, para declarar de modo bem pouco verbi-voco-visual: $\mathrm{Se}$ [sic] nasce em conflito com o mundo, ou o enfrentamos e o deglutimos, ou perecemos. (1988, p. 294).

De todas as perdas, a de mais se lamentar é a do ensaio de Clarival do Prado Valadares, "O negro brasileiro nas artes plásticas”. Seu discurso forte apontava para o risco latente que envolvia a valorização branca da arte negra, sempre sob a ameaça da encampação e da apropriação, quando não da condescendência. Radical na sua apreensão do fenômeno artístico sob uma perspectiva dos liames entre produção e sociedade, incluindo-se nesse circuito a circulação veloz ou lenta do produto, Clarival Prado Valadares exigia muito a nossa atenção quando salientava a confusão habitual entre o prestígio social do expositor (1988, p. 285) e o potencial do artista, conluio capaz de gerar uma arte domesticada, de poeticidade anódina (1988, p. 285), muito próxima da docilidade naïf. Clarival do Prado Valadares bate duro no seu ensaio, que não se limitava apenas aos compromissos entre produtor-intermediário-comprador. Sua crítica ia além e, nessa rede, apanhava o artista massificado e destinado à grande indústria pelo ensino técnico padronizado e utilitário (1988, p. 287) ou o argumento pseudocientífico que tentava explicar, pela neurologia, a maior aptidão do negro para as artes cinestésicas em detrimento das plásticas.

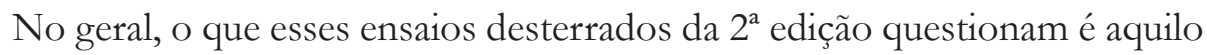
que Joel Rufino dos Santos, outro desterrado, discutia no "Prefácio" da $1^{\mathrm{a}}$ edição: a precária visibilidade do negro na sociedade brasileira. Segundo Joel Rufino, a invisibilidade do negro e do indio aparece como um pacto que não deve ser quebrado, sob pena de sermos obrigados a redefinir o Brasil (1988, p. 7).

Como parte integrante das comemorações do centenário da Abolição, em 1988, a $1^{\text {a }}$ edição de $A$ mão afro-brasileira carregava consigo o tom adequado de uma reivindicação política correndo paralela com a reivindicação estética, já que, antes dessa obra de Emanoel Araújo, nenhuma outra se aventurara a tanto em matéria de repertório e de abrangência. Com este alcance, nada encontramos em três obras que nos orientam no assunto: o Manual bibliográfico de estudos brasileiros de Rubens Borba de Moraes e de William Berrien, publicado em 1949; O negro no Brasil. Uma contribuição bibliográfica, coordenado por Lúcia Gaspar e publicado em 1994; a Enciclopédia brasileira da diáspora africana de 
Nei Lopes, publicada em 2004. Se recuarmos também a trabalhos pioneiros e gerais como o de Nina Rodrigues (Os africanos no Brasil, 1932); os de Artur Ramos (O negro brasileiro, 1934; O negro na civilização brasileira, 1956) ou os anais do $1^{\circ}$ e do $2^{\circ}$ Congresso Afro-Brasileiro (1934 e 1937), verificamos que, salvo erro, este conjunto de ensaios organizados por Emanoel Araújo é o primeiro compêndio que reúne matéria específica sobre o assunto, tanto na sua vertente erudita como na popular, sem se estranharem entre si. Bastaria esse caráter gregário e especializado para recomendar, com entusiasmo, as duas edições de $A$ mão afro-brasileira. É obra que se tornou referência no setor e a diferença de tom entre as duas edições acentuará isso, quando se fizer um inventário bibliográfico extenso a respeito.

Concentremo-nos, no entanto, nesta $2^{\mathrm{a}}$ edição.

As cinco partes de que se compõem estes dois volumes estão organizados num alinhamento histórico que vem do Brasil colonial para o contemporâneo. Embora as cinco partes não contenham número igual de capítulos, mesclam eles, de forma prudente e equilibrada, as Artes Plásticas com as coreográficas, as literárias e as musicais, de modo a cobrir espectro bastante amplo. Ao todo, são 30 capítulos. Um a mais que a $1^{a}$ edição, na qual alguns deles estavam rebaixados à condição de "apêndice". Desta vez, os oito apêndices originais foram elevados à categoria de "capítulos" e acrescidos, em boa hora, de mais um outro sobre a imprensa negra, escrito por Oswaldo de Camargo. E, nesta edição de 2010, quem assina o artigo sobre fotografia é Denise Camargo em vez de Stefania Bril.

Como a pintura e a arquitetura religiosas têm precedência histórica, são elas o centro dos séculos 17, 18 e 19 e delas dão conta renomados especialistas, que não só discutem a qualidade dos trabalhos como substanciam-nos através de documentação histórica e de análise técnica, em combinação bastante proporcional, sem sobrecarregar nenhum dos lados.

Em resenha informativa sobre obra coletiva não cabe, é claro, destacar artigos. Além do risco do melindre, corre-se o da injustiça junto com o da preterição aparente. Para evitar esse perigo o recurso é destacar as linhas de força dos ensaios, em vez de seus autores, realçando aquelas que dão corpo à reflexão, consolidando-a.

Desse modo, torna-se mais conveniente salientar dois traços importantes, bem perceptíveis em 2/3 destes ensaios, os relativos às Artes Plásticas, esteio 
desta recolha que tem como meta a afirmação estética e social de um segmento artístico.

Em primeiro lugar, atente-se para uma linguagem técnica que não se permite a concessão e que faz da terminologia específica e pontual seu recurso maior, sem exibicionismo, no entanto. Ao se voltarem para as peças em si ou para o contexto que as informa, esses ensaios fogem da condescendência e, com maior ou menor grau de assertividade, ferem o ponto que pretendem, isto é, o da produção artística negra em território brasileiro tendo em vista sua inserção universal.

No que diz respeito às peças em si, os ensaístas empenham-se em avaliá-las de acordo com critérios internos, primeiro; e externos, em seguida. De acordo com eles, o que importa é: valor estético e informativo da iconografia; gêneros favoritos; preferências temáticas; filiações estéticas; grau de criatividade, de originalidade e de imaginação; harmonia de composição e de cores; dinamismo figurativo; utilização de recursos técnicos variados; material utilizado etc.

Em alguns momentos, vêm em socorro desses critérios imanentes algumas considerações de caráter externo, que favorecem e ampliam a contextualização da obra, banhando-a de perspectiva histórica e social. Neste caso, os ensaístas recorrem à pesquisa arquivística e documental; à sobreposição do elemento europeu à tíbia tradição local; ao percurso biográfico do artista; à distribuição geográfica das pequenas comunidades artísticas; à atribuição de autoria; às técnicas de aprendizado; à organização estrutural dos ofícios exercidos pelos negros e pardos; à hierarquia no aprendizado dos ofícios; à função das corporações religiosas; aos percalços de afirmação do artesão; à condição étnica como fator de in/aceitação; à adequação do artista aos materiais locais.

Da conciliação saudável entre motivos internos e externos nascem respostas, mesmo que provisórias, a questões de envergadura, menos preocupadas com a conjuntura e mais voltadas para a estrutura da produção, objetivo derradeiro desta magnífica coletânea, cuja nomeação metonímica sumaria seu significado altamente simbólico. Afinal, se o escravo colaborou para construir a riqueza brasileira com suas mãos, nada mais justo que sejam elas o centro singular do título deste cimélio organizado por Emanoel Araújo.

Do meio de suas páginas erguem-se várias respostas a uma questão chave que bem sumaria o sentido dessa miscigenação estética. Num determinado momento, José Luiz Mota Menezes se pergunta: O negro, aquele que se voltou 
para as obras de construção ou as artes plásticas, trabalhando como escravo ou liberto, até que ponto transferiu sua visão estética e sua força criativa para a produção cultural do Brasil? (2010, p. 1-117).

A essa questão magna, que toca direto na questão dos desdobramentos da migração e da fricção cultural, cola-se uma outra, cuja amplitude ultrapassa o território imediato, projetando a arte produzida pela mão negra em espaço mais universal e, portanto, menos vulnerável a considerações eventualmente condescendentes. Quando Lélia Coelho Frota argumenta que seu esforço ensaístico é tentativa esquemática de procurar evidenciar a complexa tarefa de dar conta das diversidades culturais do país e que, nessa tentativa, o que pretende é enfatizar [...] os universos culturais a serem entendidos como sistemas, como um todo coerente, repletos de códigos carregados de significados próprios (2010, p. 1-312), consagra-se o princípio da apreensão estética independente de suas marcas ou estigmas de origem.

É nesse alto patamar de discussão - que encarece o contexto social de onde provêm os artefatos, mas que também não os explica tão somente por essa via - que se insere a maioria dos textos coligidos por Emanoel Araújo e assinados por críticos como Myrian Andrade Ribeiro de Oliveira, Lélia Coelho Frota, Aracy Amaral, José Roberto Teixeira Leite, José Luiz Mota Menezes, Olinto Rodrigues dos Santos Filho, Jaelson Bitran Trindade e outros. Ou os artigos dedicados à arte musical, teatral, literária e à dança de autoria de Oswaldo de Camargo, Sérgio Cabral, Haroldo Costa, Claver Filho e Abdias do Nascimento, falecido há pouco, bem próximo de seus cem gloriosos anos de luta e de dedicação à causa negra.

As páginas finais do $2^{\circ}$ volume fecham-se com dois repertórios muito úteis, porque coligem informações biográficas ou bibliográficas. Em um deles, Carlos Eugênio Marcondes de Moura apresenta "O negro na formação cultural do Brasil: Tentativa de nominata e iconografia", onde o elenco farto de nomes e de fotos torna-se ponto de partida obrigatório de pesquisa de agora em diante. Por sua vez, a tentativa de bibliografia para "As artes plásticas dos negros no Brasil", organizado por Áurea Pereira da Silva, inscreve-se nessa mesma dimensão de utilidade e de informação, apreciável como dispositivo inicial para outra pesquisa em torno da arte negra brasileira. No final de cada volume vem a tradução, para o inglês, dos ensaios. 
Poucos anos depois da inauguração do Museu Afro Brasil de São Paulo, Emanoel Araújo prefaciou um livro dedicado àquela instituição. Desse prefácio salta uma frase que é afirmação de vontade e profissão de fé realizada: O Museu Afro Brasil é, portanto, um museu bistórico, que fala das origens, mas atento a identificar na ancestralidade a dinâmica de uma cultura que se renova mesmo na exclusão (Musen Afro Brasil. São Paulo: Banco Safra, 2010, p. 10).

Esta declaração de princípios, se a juntarmos a uma outra, dão-nos as duas a qualidade deste empreendimento editorial e intelectual.

Em um dos depoimentos, um velho escultor popular de Pernambuco, antigo aprendiz nas oficinas de Mestre Vitalino, explica, de modo sintético e poético, porque abandonou o barro, trocando-o pela madeira e pela folha de zinco. $\mathrm{Na}$ sua opinião, o barro é menos versátil, menos flexível, menos eloquente. Foi por esse motivo que Nhô Caboclo dispensou-o. E sua explicação vem sem rodeios: Gosto de peça que bula, peça valente, peça braba. Peça manual (2010, p. 1-321).

Não há dúvida de que, mais uma vez, Emanoel Araújo construiu com esta mão afro-brasileira mais uma peça que bula.

Recebido em 10 de setembro e aprovado em 15 de setembro de 2010. 